\title{
Perceived Autonomy Support and Basic Psychological Needs of Participants in a Women's Health-Related Exercise Programme according to Exercise Stage of Change and Exercise Type
}

\author{
Shabnam Mehrtash ${ }^{1}$, Mustafa Levent Ince
}

Affiliations: 'Middle East Technical University, Physical Education and Sports Department, Ankara, Turkey

Correspondence: M. Levent Ince, Middle East Technical University, Faculty of Education, Physical Education and Sports Department, Beden Eğitimi ve Spor Bölümü, 06800 Ankara, Turkey. E-mail: m.levent.ince@gmail.com

ABSTRACT This study applied the self-determination theory to examine the perceived autonomy support and basic psychological needs of women participating in a health-related exercise programme with respect to exercise stage of change (three stages including Preparation, Action, and Maintenance) and exercise type (Aerobic vs Strength \& Flexibility). The sample consisted of 316 women ( $M$ age=25.1 years, SD=7.2) who completed the Perceived Autonomy Support Scale for Exercise Settings: Basic Psychological Needs in Exercise Scale and the Physical Activity Stages of Change Questionnaire. Participants' heart rate during the exercise and the exercise content were used to categorize the exercise classes as Aerobic or Strength \& Flexibility. Data were analysed using ANOVA and MANOVA $(p<.05)$. The findings indicated that participants perceived autonomy support differed according to exercise type $\left(F(1,315)=6.44, p<.05, \eta^{2}=.02\right)$. Moreover, participants' basic psychological needs differed according to both exercise stage of change $\left(F(3,311)=3.97, p<.05, \eta^{2}=.04\right)$ and exercise type $\left(F(3,312)=5.63, p<.05, \eta^{2}=.05\right)$. To address the needs of worksite health-related exercise programme participants, programme providers and instructors should further consider exercise stages of change and participants' preferred type of exercise.

KEY WORDS women, self-determination theory, exercise stages, exercise type, worksite health promotion

@MJSSMontenegro

WOMEN HEALTH-RELATED EXERCISE PROGRAMMES

http://mjssm.me/?sekcija=article\&artid=151

\section{Introduction}

Participation in physical activity has decreased among adults, and the prevalence of a number of health problems has increased, especially in industrialized countries. These trends have led researchers to explore the motivational aspects of physical activity to improve participation among adults. As the majority of adults spend most of their daily life at work, organizing worksite health-related exercise programmes might be beneficial for promoting employees' level of physical activity.

Worksites offer different health promotion programmes that aim to enhance the health and wellbeing of employees and their families. The effects of worksite physical activity interventions on increasing physical activity levels among adults have been examined by different researchers (Shephard, 2002; Proper et al., 2002; Abraham \& Graham-Rowe, 2009). According to recent reviews and reports from the World Health Organization, worksites are a preferred setting for promoting the health and physical activity levels of adults (Dugdill, Brettle, Hulme, McCluskey \& Long, 2008; Abraham \& Graham-Rowe, 2009). In addition, different researchers (Anderson et al., 2009; Conn et al., 2009, Crump, Earp, Kozma \& Picciotto, 1996) have confirmed the benefits of worksite health promotion (WHP) programmes regarding employees' behaviour.

(C) 2017 by the author(s). License MSA, Podgorica, Montenegro. This article is an open access article distributed under the terms and conditions of the Creative Commons Attribution (CC BY).

Conflict of interest: None declared. 
The effect of health-related exercise programmes, such as those providing fitness (Rebold, Kobak, Peroutky \& Glickman, 2015), aerobic (Korshøj et al., 2015) and yoga classes (Cowen, 2010), has been examined in different worksite populations, including academic staff, cleaners, and firefighters. These studies identified a positive effect of these interventions on both physical and mental health outcomes. In addition to enhancing employees' cardiorespiratory and muscular endurance performance, these WHP programmes may help participants focus on their work and may relieve work stress.

Women are currently employed in a number of different positions in addition to having family-related roles and responsibilities. Therefore, the interactions between their work and family and stressful environments may affect women's general health and work ability (Collins, Hollander, Koffman, Reeve \& Seidler, 1997). However, despite the importance of physical activity for women who are employed, previous studies have shown that employed women engage in a lower percentage of regular participation in exercise than the general population (Lee, Djoussé, Sesso, Wang, \& Buring, 2010). Pohjonen and Ranta (2001) determined that worksite programmes have the potential to improve physical activity levels, address the lack of time for exercise, and prevent decreases in work ability among female workers.

Although studies have examined the effects of worksite health-related physical activity for over two decades, few researchers have considered the motivational aspects involved in increasing employees' engagement in physical activity. Examining the women's worksite-health related physical activity setting with self-determination theory constructs with respect to exercise stages of change construct of Transtheoretical Model and preferred type of exercise (Aerobic vs Strength \& Flexibility) may strengthen understanding of the topic.

The self-determination theory provides a multidimensional approach to identifying reasons for participation in physical activity (Deci \& Ryan, 2008). According to the self-determination theory, adults with a more intrinsic form of motivation for exercise have greater intention to regularly participate than people with extrinsic purposes do (Ryan \& Deci, 2008). If the environment supports more autonomy, individuals will feel autonomous rather than controlled (Gagne, 2003). Perceptions of autonomy support by different individuals such as coaches, fitness instructors, and peers could increase the internalization of the three psychological needs (autonomy, competence, and relatedness) of exercise participants in health-related physical activity programmes (Ryan \& Deci, 2008).

According to the Transtheoretical Model, exercise participants in different stages of change (Preparation (people who have recently started participating in regular exercise), Action (people who have participated in regular exercise for more than 1 month to less than 6 months), Maintenance (people who have participated in exercise for more than 6 months) need different motivational approaches from their instructors (Prochaska $\&$ DiClemente, 1984). In addition, previous researchers also claimed that motivation to participate in exercise depends on the exercise type and intensity and the individual's stage of participation (Frederick, Morrison, \& Manning, 1996; Duncan, Hall, Wilson \& Jenny, 2010).

Considering the abovementioned findings, the aim of this study was to examine the perceived autonomy support and basic psychological needs of participants in women's health-related exercise programmes, considering exercise stage of change (Preparation, Action, and Maintenance) and preferred exercise type (Aerobic vs. Strength \& Flexibility), using a university sports centre as the WHP setting. This study addressed four research questions: 1) What is the effect of the exercise stage of change on the perceived autonomy support of participants in a women's health-related exercise programme? 2) What is the effect of the preferred exercise type on perceived autonomy support among participants in a women's health-related exercise programme? 3 ) What is the effect of the exercise stage of change on the basic psychological needs of participants in a women's health-related exercise programme? and 4) What is the effect of the preferred exercise type on the basic psychological needs of participants in a women's health-related exercise programme?

\section{Method}

\section{Participants}

This study was conducted at a university, which functioned as the WHP setting. A total of 1697 people participated in health-related exercise programmes during the study period (2013-2014 spring semester), including academic and administrative staff and students. Data were collected from 369 participants in Zumba, Power Step, Pilates, Freestyle Tempo, Freestyle Combat, Yoga, and Total Body classes who volunteered to participate in this study. Data were initially screened for incomplete responses, resulting in the exclusion of 53 respondents. A total of 316 women participated in this study. Their mean age was 25.1 years $(\mathrm{SD}=7.2)$, with a range from 18 to 65 years.

\section{Data Collection Instruments}

Quantitative data were collected with three instruments: 1) The Perceived Autonomy Support Scale for Exercise Settings (PASSES), 2) the Basic Psychological Needs in Exercise Scale (BPNES), and 3) the Physical Activity Stages of Change Questionnaire (PASCQ).

Perceived Autonomy Support Scale for Exercise Settings (PASSES)

PASSES was used to measure the perception of autonomy support in exercise settings in terms of the instructors and was developed by Hagger et al. (2007). The items are scored on a seven-point Likert scale 
ranging from 1 (strongly disagree) to 7 (strongly agree). It is one-dimensional and consists of 12 items (e.g. my health-related exercise instructor encourages me to engage in active sports and/or vigorous exercise in my free time). The validity of this scale has been assessed through a cross-cultural investigation, and the results indicated that it was valid for use in exercise settings for young people (Hagger et al., 2007). This scale was adapted to Turkish by Müftüler and İnce (2015); according to their findings, the Turkish version has good internal consistency $(\alpha=.97)$ and construct validity.

Basic Psychological Needs in Exercise Scale (BPNES)

The BPNES is a self-report instrument developed by Vlachopoulos and Michailidou (2006). It consists of 12 items that assess the extent to which psychological needs related to autonomy (4 items), competence (4 items), and relatedness (4 items) are satisfied in an exercise context. Example items for each sub-scale include the following: "The exercise programme I follow is highly compatible with my choices and interests" for autonomy; "I feel I have been making substantial progress with respect to the end results I am pursuing" for competence; and "I feel extremely comfortable with the other exercise participants" for relatedness. The items are scored on a five-point Likert scale ranging from 1 (I do not agree at all) to 5 (I completely agree). The reliability and validity of this scale across cultures including Turkish were assessed in a cross-cultural investigation (Vlachopoulos \& Michailidou, 2006). The internal consistency of the scale in the Turkish population was $\alpha=.62$ for autonomy, $\alpha=.77$ for competence, and $\alpha=.69$ for relatedness (Vlachopoulos et al., 2013).

Physical Activity Stages of Change Questionnaire (PASCQ)

The PASCQ was used to evaluate participants' physical activity stage. This questionnaire was developed by Marcus, Rossi, Selby, Niaura, and Abrams (1992) and is a binary questionnaire. The results were used to classify participants into five different groups according to the scoring algorithm: Pre-contemplation (unaware of their problematic behaviour and lack of intention to participate in an activity), Contemplation (intention to change the behaviour within six months, but no commitment to participate in an activity), Preparation (intention to participate in an activity in the next month without successful action in the past year), Action (changed behaviour and participation in an activity from one day to six months), and Maintenance (continuation of an activity for more than six months). The test-retest reliability (ICC=.80) and construct validity of the Turkish version of the PASCQ were reported by Cengiz, Asci, and İnce (2010).

\section{Categorization of Preferred Exercise Type}

Latin Aerobics, Zumba, Power Step, Tempo, Freestyle Combat, Total Body, Yoga, and Pilates classes were offered by the worksite exercise programme and were visited by the lead researcher. The exercise classes were first observed, and then the instructors of each class were asked about the main purpose of the class. Based on the observation and instructors' report, the exercise programmes were grouped into two main categories: 1) aerobic-oriented classes including Latin Aerobics, Zumba, Power Step, Tempo, and Freestyle Combat, and 2) muscular strength and flexibility-oriented classes including Yoga, Pilates, and Total Body.

One session of each class was then visited. Volunteer participants (Latin Aerobics $(n=8)$; Zumba $(n=13)$; Power Step ( $n=14)$; Tempo $(n=8)$; Freestyle Combat $(n=11)$; Total Body $(n=8)$; Yoga $(n=14)$ and Pilates $(n=6))$

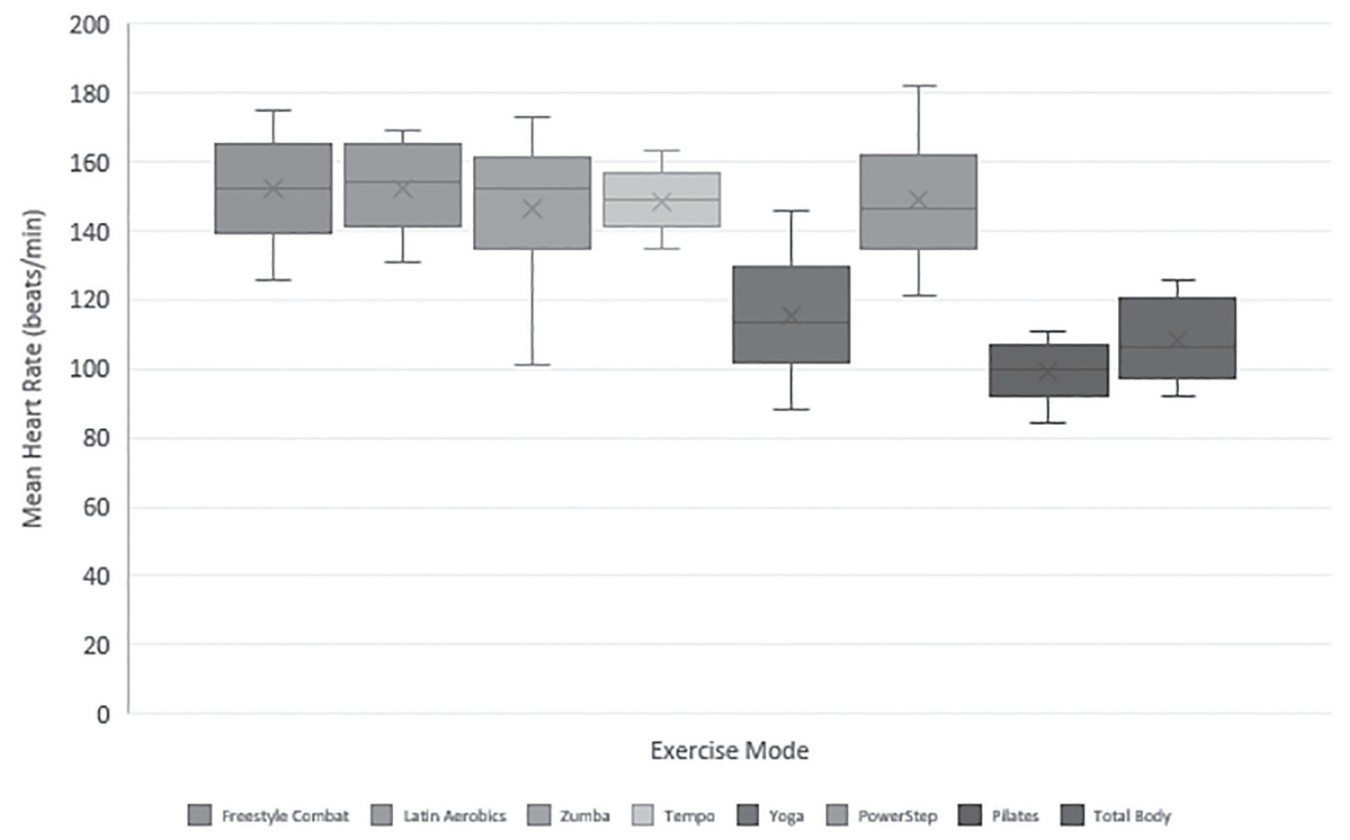

FIGURE 1. Participants' Mean Heart Rate/Min by Exercise Type 
wore heart rate monitors with data storage capability (Polar RJ 300X). Data were transferred to a computer and analysed using descriptive statistics to examine the participants' mean, maximum and minimum heart rate/min during the entire session. Based on the findings, participants in aerobic activities had a higher mean heart rate/min during the exercise sessions (Latin Aerobics $=152.25 \pm 13.76, \mathrm{Zumba}=146.31 \pm 19.83$, Power Step $=148.93 \pm 17.08$, Tempo $=148.63 \pm 9.62$, and Freestyle Combat $=152.27 \pm 15.55$ ) than the values of participants in the strength and flexibility activities (Yoga $=115.07 \pm 17.09$, Pilates $=99.17 \pm 9.57$, and Total Body $=108.00 \pm 12.18$ ) (see Figure 1).

\section{Data Collection Procedure}

After the study was approved by the Human Subjects Ethics Committee (Approval No: 28620816/168-327), the researcher visited the Zumba, Power Step, Pilates, Tempo, Freestyle Combat, Yoga and Total Body Step classes offered by the Sports Directory of the University under the health-related exercise programme. The researcher explained the aims of the study and asked for voluntary participation. Volunteer participants completed the study questionnaires at the end of their class and returned them to the researcher. Participants completed the questionnaires in approximately 10 minutes.

\section{Data Analysis}

First, descriptive statistics were conducted, and the means and standard deviations were generated. After the assumptions of normality and homogeneity of variance were checked for the univariate and multivariate analyses, ANOVA was used to analyse the first and second research questions, and MANOVA, the third and fourth research questions $(p<.05)$.

\section{Results}

The first research question aimed to examine perceived autonomy support among participants in the healthrelated fitness programme according to exercise stage. According to the ANOVA, health-related fitness participants' perceived autonomy support did not significantly differ according to exercise stage ( $F$ (2, $315)=2.55, p>.05)$.

The second research question aimed to examine participants' perceived autonomy support according to their preference for aerobic or strength- and flexibility-type activities. The ANOVA results for the second research question indicated that aerobic exercise participants had significantly higher perceived autonomy support than strength and flexibility exercise participants $\left(F(1,315)=6.44, p<.05, \eta^{2}=.02\right)$. Mean value of the aerobic type of exercise participants was higher $(M=71.81, S D=10.70)$ than the mean value of strength and flexibility type of exercise participants $(M=68.59, S D=11.89)$ (Table 1$)$.

\begin{tabular}{llcc} 
TABLE 1. Descriptive Statistics of PASSES by Stages of Change and Preferred Exercise Type. & \\
Variable & Stages of Change & $\boldsymbol{M}$ & SD \\
\hline PASES \& Stages of Change & Preparation (P) & 68.26 & 11.98 \\
& Action (A) & 71.55 & 12.21 \\
& Maintenance (M) & 71.14 & 10.03 \\
& Total & 70.32 & 11.37 \\
\hline & Exercise Type & & \\
\hline PASES \& Preferred Exercise Type * & Aerobic (A) & 71.81 & 10.70 \\
& Strength \& Flexibility (S\&F) & 68.59 & 11.89 \\
& Total & 70.32 & 11.37 \\
\hline
\end{tabular}

Note: *Significant difference $(p<.05)$

The third research question aimed to examine the basic psychological needs of participants in the healthrelated exercise programme according to exercise stage of change. The MANOVA results indicated that the basic psychological needs of these participants differed significantly according to exercise stage of change (Pillai's Trace $\left.=.07, F(3,311)=3.97, p<.05, \eta^{2}=.04\right)$. The post hoc test revealed that participants in the maintenance stage had significantly higher mean values of the autonomy $(M=16.21, S D=2.69)$, competence $(M=16.55, S D=2.52)$ and relatedness $(M=17.06, S D=2.30)$ subscales than the mean values of participants in the preparation stage (autonomy: $M=14.71, S D=2.63$ ), competence: $M=15.68, S D=2.21$, and relatedness: $M=15.94, S D=2.13$ ) (Table 2).

The fourth research question aimed to examine the basic psychological needs of health-related exercise programme participants according to their preference for aerobic or strength- and flexibility-type activities. According to the MANOVA, there were significant differences between participants who preferred aerobic exercise and those who preferred strength and flexibility activities in perceived autonomy, competence and relatedness (Pillai's Trace $\left.=.05, F(3,312)=5.63, p<.05, \eta^{2}=.05\right)$. Participants in aerobic activities had higher perceived autonomy $(M=16.06, S D=2.62)$, competence $(M=16.57, S D=2.26)$, and relatedness $(M=16.89$, 


\begin{tabular}{|c|c|c|c|c|c|}
\hline Variables & Sub-Scale & Stages of Change & $M$ & $S D$ & $\begin{array}{l}\text { Significant differences } \\
p<.05\end{array}$ \\
\hline \multirow{13}{*}{$\begin{array}{l}\text { BPNES \& Stages of } \\
\text { Change }\end{array}$} & \multirow[t]{4}{*}{ Autonomy* } & Preparation (P) & 14.71 & 2.63 & \multirow[t]{4}{*}{$\mathrm{P}<\mathrm{M}$} \\
\hline & & Action $(A)$ & 15.52 & 2.49 & \\
\hline & & Maintenance (M) & 16.21 & 2.69 & \\
\hline & & Total & 15.53 & 2.69 & \\
\hline & \multirow[t]{4}{*}{ Competence* $^{*}$} & Preparation (P) & 15.68 & 2.21 & \multirow[t]{4}{*}{$\mathrm{P}<\mathrm{M}$} \\
\hline & & Action (A) & 16.30 & 2.77 & \\
\hline & & Maintenance (M) & 16.55 & 2.52 & \\
\hline & & Total & 16.20 & 2.52 & \\
\hline & \multirow[t]{4}{*}{ Relatedness* } & Preparation (P) & 15.94 & 2.13 & \multirow[t]{4}{*}{$\mathrm{P}<\mathrm{M}$} \\
\hline & & Action (A) & 16.30 & 2.30 & \\
\hline & & Maintenance (M) & 17.06 & 2.30 & \\
\hline & & Total & 16.49 & 2.29 & \\
\hline & & Exercise Type & & & \\
\hline \multirow{9}{*}{$\begin{array}{l}\text { BPNES \& } \\
\text { Preferred Exercise } \\
\text { Type }\end{array}$} & \multirow[t]{3}{*}{ Autonomy* } & Aerobic (A) & 16.06 & 2.62 & \multirow[t]{3}{*}{$A>S \& F$} \\
\hline & & Strength \& Flexibility (S\&F) & 14.92 & 2.63 & \\
\hline & & Total & 15.53 & 2.68 & \\
\hline & \multirow[t]{3}{*}{ Competence* $^{*}$} & Aerobic (A) & 16.57 & 2.26 & \multirow{3}{*}{$A>S \& F$} \\
\hline & & Strength \& Flexibility (S\&F) & 15.77 & 2.73 & \\
\hline & & Total & 15.20 & 2.52 & \\
\hline & \multirow[t]{3}{*}{ Relatedness* } & Aerobic (A) & 16.89 & 2.21 & \multirow[t]{3}{*}{$A>S \& F$} \\
\hline & & Strength \& Flexibility (S\&F) & 16.03 & 2.30 & \\
\hline & & Total & 16.48 & 2.91 & \\
\hline
\end{tabular}

Note: *Significant difference $(p<.05)$

$S D=2.21)$ scores than the scores of participants in strength and flexibility activities (autonomy: $M=14.92$, $S D=2.63$ ), competence: $M=15.77, S D=2.73$, and relatedness: $M=16.03, S D=2.30)(p<.05)$ (Table 2).

\section{Discussion}

The results indicated a non-significant difference in perceived autonomy support of WHP programme participants based on their exercise stage of change, whereas perceived autonomy support differed significantly between participants based on their preferred type of exercise. Specifically, participants in aerobic exercise classes had a higher mean score for perceived autonomy support than participants in strength and flexibility classes did.

Moreover, the findings indicated that the basic psychological needs of the WHP programme participants differed significantly according to their stage of change and preferred type of exercise. Further analyses demonstrated that participants in the maintenance stage had significantly higher mean scores for basic psychological needs than those in the preparation stage. Furthermore, aerobic exercise participants had higher basic psychological needs scores than participants in strength and flexibility classes did.

The results of a systematic literature review conducted by a group of researchers (Teixeira, Carraca, Markland, Silva \& Ryan, 2012) indicated the value of the self-determination theory in realizing the exercise behaviour and the importance of autonomous forms of motivation in fostering long-term exercise adherence. Moreover, different studies (Mullan et al., 1997; Daley \& Duda, 2006) have shown that an increase in autonomous motivation has a positive effect on advancing the exercise stage of change of exercise participants. For instance, the relationship between self-determined exercise behaviour and exercise stage of change in adults was explored by Mullan et al., (1997) and self-determination was found to increase from the lower to higher stages of change. Very similar outcomes were reported by Daley and Duda (2006). They claimed that participants who were in the early stages had a less self-determined form of motivation than participants in higher stages of change.

Although Mullen et al. (1997) reported a positive relationship between self-determined exercise behaviour and the exercise stage of change, the difference in basic psychological needs between health-related physical activity programme participants in different stages of change has not been described in previous studies. The significant results obtained in this study indicated that the basic psychological needs of participants change with their exercise stage of change. 
Most participants begin exercising for instrumental reasons such as improving their health and fitness, increasing their muscular endurance and strength or losing weight, but they may not be sufficiently engaged in these activities to continue performing them. There is a lack of information on the difference in perceived autonomy support of health-related physical activity participants according to their preferred exercise. In the current study, these two variables were significantly related. Moreover, the results showed that participants in the aerobic exercise had higher perceived autonomy support than participants in strength- and flexibilitytype exercise. Therefore, providers of women's WHP programmes should consider autonomy support-related issues (e.g. instructors' behaviour) in strength and flexibility exercise classes.

Several limitations should be considered when interpreting the findings of this study. First, participants' perceived autonomy support, basic psychological needs, and exercise stages were determined by surveys. Therefore, the related data depend on the trustworthiness of their responses. Second, the findings of this study represent the Turkish university setting as one context for a WHP programme, and the findings may not be generalizable to other settings.

In conclusion, based on the results of this study, providers and instructors involved in women's WHP programmes should focus on certain factors. First, instructors should attempt to provide a climate that supports participants' perceived autonomy based on the needs of each participant's stage of change and preferred type of exercise. Second, as aerobic activities better met the participants' basic psychological needs compared with the strength and flexibility exercise classes, providers and instructors in these programmes should further consider the basic psychological needs of participants in strength and flexibility exercise classes.

\section{REFERENCES}

Abraham, C., \& Graham-Rowe, E. (2009). Are worksite interventions effective in increasing physical activity? A systematic review and meta-analysis. Health Psychology Review, 3(1), 108-144.

Anderson, L. M., Quinn, T. A., Glanz, K., Ramirez, G., Kahwati, L. C., \& Johnson, D. B. (2009). The effectiveness of worksite nutrition and physical activity interventions for controlling employee overweight and obesity: a systematic review. American Journal of Preventive Medicine, 37(4), 340-357.

Cengiz, C., Aşçı, F. H., \& İnce, M. L. (2010). Exercise stages of change questionnaire: its reliability and validity. Türkiye Klinikleri Spor Bilimleri, 2(1), 32-37.

Collins, B. S., Hollander, R. B., Koffman, D. M., Reeve, R., \& Seidler, S. (1997). Women work and health: issues and implications for worksite health promotion. Women \& Health, 25(4), 3-38.

Conn, V. S., Hafdahl, A. R, Cooper, P. S., Brown, L. M., \& Lusk, S. L. (2009). Meta-analysis of workplace physical activity interventions. American journal of preventive medicine, 37(4), 330-339.

Cowen, V. S. (2010). Functional fitness improvements after a worksite based yoga initiative. Journal of Bodywork and Movement Therapies, 14(1), 50-54.

Crump, C. E., Earp, J. A. L., Kozma, C. M., \& Hertz-Picciotto, I. (1996). Effect of organization-level variables on differential employee participation in 10 federal worksite health promotion programs. Health Education \& Behavior, 23(2), 204-223.

Deci, E. L., \& Ryan, R. M. (2008). Self-determination theory: A macro-theory of human motivation, development, and health. Canadian psychology, 49(3), 182.

Daley, A. J., \& Duda, J. L. (2006). Self-determination, stage of readiness to change for exercise, and frequency of physical activity in young people. European Journal of Sport Science, 6(4), 231-243.

Dugdill, L., Brettle, A., Hulme, C., McCluskey, S., \& Long, A. F. (2008). Workplace physical activity interventions: a systematic review. International Journal of Workplace Health Management, 1(1), 20-40.

Duncan, L. R., Hall, C. R., Wilson, P. M., \& Jenny, O. (2010). Exercise motivation: a cross-sectional analysis examining its relationships with frequency, intensity, and duration of exercise. International Journal of Behavioral Nutrition and Physical Activity, 7(1), 7.

Frederick, C. M., Morrison, C., \& Manning, T. (1996). Motivation to participate, exercise affect, and outcome behaviors toward physical activity. Perceptual and Motor Skills, 82(2), 691-701.

Gagne, M. (2003). Autonomy support and need satisfaction in the motivation and well-being of gymnasts. Journal of Applied Sport Psychology, 15(4), 372-390.

Hagger, M. S., Chatzisarantis, N. L., Hein, V., Pihu, M., Soós, I., \& Karsai, I. (2007). The perceived autonomy support scale for exercise settings (PASSES): Development, validity, and cross-cultural invariance in young people. Psychology of Sport and Exercise, 8(5), 632-653.

Korshøj, M., Lidegaard, M., Skotte, J. H., Krustrup, P., Krause, N., Søgaard, K., \& Holtermann, A. (2015). Does aerobic exercise improve or impair cardiorespiratory fitness and health among cleaners? A cluster randomized controlled trial. Scandinavian Journal of Work, Environment and Health, 41(2), 140-152.

Lee, I. M., Djoussé, L., Sesso, H. D., Wang, L., \& Buring, J. E. (2010). Physical activity and weight gain prevention. Jama, 303(12), 1173-1179.

Marcus, B. H., Rossi, J. S., Selby, V. C., Niaura, R. S., \& Abrams, D. B. (1992). The stages and processes of exercise adoption and maintenance in a worksite sample. Health psychology, 11(6), 386.

Müftüler, M., \& İnce, M. L. (2015). Use of Trans-Contextual Model-Based Physical Activity Course in Developing Leisure-Time Physical Activity Behavior of University Students. Perceptual and Motor Skills, 121(1), 31-55. 
Mullan, E., Markland, D., \& Ingledew, D. K. (1997). A graded conceptualization of self-determination in the regulation of exercise behavior: Development of a measure using confirmatory factor analytic procedures. Personality and Individual Differences, 23(5), 745-752.

Pohjonen, T., \& Ranta, R. (2001). Effects of worksite physical exercise intervention on physical fitness, perceived health status, and work ability among home care workers: five-year follow-up. Preventive Medicine, 32(6), 465-475.

Prochaska, J. O., \& DiClemente, C. C. (1984). Self change processes, self efficacy and decisional balance across five stages of smoking cessation. Progress in Clinical and Biological Research, 156, 131-140.

Proper, K. I., Staal, B. J., Hildebrandt, V. H., Van der Beek, A. J., \& Van Mechelen, W. (2002). Effectiveness of physical activity programs at worksites with respect to work-related outcomes. Scandinavian Journal of Work, Environment \& Health, 75-84.

Rebold, M. J., Kobak, M. S., Peroutky, K., \& Glickman, E. L. (2015). The Effects of a 12-Week Faculty and Staff Exercise Program on Health-Related Variables in a University Setting. International Journal of Exercise Science, 8(1), 49-56.

Ryan, R. M., \& Deci, E. L. (2008). Self-determination theory and the role of basic psychological needs in personality and the organization of behavior.Handbook of personality: Theory and research, 3, 654-678.

Shephard, R. J. (2002). Issues in worksite health promotion: A personal viewpoint. Quest, 54(1), 67-82.

Teixeria P.J., Carraca E.V., Markland D., Silva M.N. \& Ryan R.M. (2012). Exercise, physical activity, and selfdetermination theory: a systematic review. Int J Behav Nutr Phys Act, 9, 78.

Vlachopoulos, S. P., Asci, F. H., Cid, L., Ersoz, G., González-Cutre, D., Moreno-Murcia, J. A., \& Moutão, J. (2013). Cross-cultural invariance of the basic psychological needs in exercise scale and need satisfaction latent mean differences among Greek, Spanish, Portuguese and Turkish samples. Psychology of Sport and Exercise, 14(5), 622-631.

Vlachopoulos, S. P., \& Michailidou, S. (2006). Development and initial validation of a measure of autonomy, competence, and relatedness in exercise: The Basic Psychological Needs in Exercise Scale. Measurement in Physical Education and Exercise Science, 10(3), 179-201. 